\title{
Rescue of the tail defect of Brachyury mice
}

\author{
David Stott, ${ }^{1,2}$ Andreas Kispert, and Bernhard G. Herrmann \\ Max-Planck-Institut für Entwicklungsbiologie, 7400 Tübingen, Germany
}

\begin{abstract}
The mouse Brachyury $(T)$ gene is required for normal development of axial structures. Embryos homozygous for the $T$ mutation show severe deficiencies in mesoderm formation. They lack the notochord and allantois, have abnormal somites, and die at $\sim 10$ days postcoitum probably as a result of the allantois defect. Mice heterozygous for the $T$ mutation exhibit a variable short-tailed phenotype. The $T$ gene has been cloned and shown to be expressed in the tissues most strongly affected by the mutation. In this paper, we show that a single-copy transgene representing the wild-type $T$ allele is able to rescue the $T$-associated tail phenotype. In addition, we show that increasing dosage of the $T$ gene in $T^{c} /+$ mice causes an increased extension of the axis. These data show the correlation of the level of $T$ product with the extension of the anteroposterior axis, directly demonstrating the involvement of the $T$ product in this process.
\end{abstract}

[Key Words: Brachyury; mouse development; phenotypic rescue; axis; mouse embryo; tail interaction factor]

Received September 24, 1992; revised version accepted November 17, 1992.

Identification and cloning of genes encoding products required for essential developmental processes has proved to be a productive route toward understanding the mechanisms underlying cellular differentiation and pattern formation during animal development. In the case of the mammalian embryo, long life cycles, intrauterine development, and genome size mitigate against genetic screens to identify large numbers of loci encoding different functional components involved in particular events. An alternative approach is to work from the product of a single locus shown to be required for an event in an attempt to understand its role in development and, subsequently, identify interacting components. We have chosen to study the action of the product of a gene, Brachyury or $T$, which is known from the phenotype of mutant strains of mice to be required for the processes of mesoderm formation and anteroposterior axis elaboration in the mammalian embryo (Chesley 1935; Gluecksohn-Schoenheimer 1944; Spiegelman 1976). This gene has been cloned (Herrmann et al. 1990) and shown to be expressed in the embryonic tissues most strongly affected by the mutation (Wilkinson et al. 1990; Herrmann 1991). The availability of several mutant $T$ alleles plus the cloned gene sequences allow access to the study of the function of this gene during axis formation.

Before the appearance of the primitive streak, the mammalian embryo consists of a two-layered cylinder possessing obvious proximal distal polarity with reference to maternal tissues, but apparent radial symmetry

\footnotetext{
${ }^{1}$ Corresponding author.

2Present address: Animal Molecular Genetics Group, Department of Biological Sciences, University of Warwick, Coventry, CV4 7AL, U.K.
}

about this axis. The inner layer of cells, referred to as the primitive ectoderm or epiblast, is thought to give rise to all structures of the embryo proper (Gardner and Papaioannou 1975; Gardner and Rossant 1979; Gardner et al. 1985; Beddington et al. 1989), whereas the outer layer, the visceral endoderm, appears essentially not to contribute to the embryo (Lawson et al. 1991). This cylinder is surrounded by the parietal yolk sac, composed of parietal endoderm and trophoblast cells, which interacts directly with maternal tissues. The first indication of the anteroposterior axis of the developing embryo is the appearance of the primitive streak, which forms initially about halfway along the length of the cylinder and extends, in the space of $\sim 8 \mathrm{hr}$, to the distal tip. The streak is a region of the egg cylinder where cells leave the inner layer-referred to as the epiblast or primitive ectoderm-to migrate away between the two layers of the cylinder $(\mathrm{Na}-$ katsuji et al. 1986) eventually forming paraxial mesoderm and other mesodermal cell types. The appearance of the primitive streak defines the posterior end of the axis, which is initially U-shaped, running from the primitive streak around the distal tip to the future anterior of the embryo on the other side of the cylinder. After extension of the primitive streak, a structure forms at the distal tip of the egg cylinder, referred to as the archenteron or node. At the node, cells also emerge from the inner layer but, instead of migrating between the two pre-existing layers, remain at the midline and intercalate into the visceral endoderm layer to form axial mesoderm, the notochordal plate, and subsequently notochord (Jurand 1974; Lawson et al. 1991).

In $T$ mutant embryos, all mesodermal cell types are defective. Whereas mice heterozygous for a deletion at 
the Brachyury locus display a viable short-tailed phenotype, embryos homozygous for the null allele, $T$, form insufficient axial and paraxial mesoderm resulting in the failure of the extension of the axis during early organogenesis and subsequent embryonic mortality, probably owing to inability to form the allantois (Chesley 1935; Gluecksohn-Schoenheimer 1938; Grueneberg 1958; Yanagisawa et al. 1981). Abnormalities of the neural tube are probably the result of secondary effects resulting from the notochord deficiency. Analysis of the severity of the phenotype resulting from different $T$ alleles has led to the proposal that continuing axial elaboration requires increasingly high doses of the $T$ product (MacMurray and Shin 1988; Yanagisawa 1990). In addition, the recent observation that expression of the Xenopus homolog of Brachyury is an immediate early response to a signal that mimics mesoderm induction in vitro, supports the proposal that the Brachyury product plays a key role in the establishment and elaboration of the mesoderm and, hence, of the anteroposterior axis (Smith et al. 1991).

In this work we show that a single-copy transgene including all transcribed sequences of the Brachyury gene, is sufficient to completely rescue the short tailed phenotype of mice heterozygous for the $T$ mutation, establishing beyond doubt that the cloned gene responsible for the observed phenotype. Furthermore, by manipulating the copy number of the $T$ gene in transgenic mice, we show a direct correlation between levels of $T$ product and axial extension.

\section{Results}

Generation of transgenic mice carrying an extra copy of the mouse $\mathrm{T}$ gene

Previously, we have cloned a gene which, based on the alteration of its transcription unit in the $T^{\text {Wis }}$ allele and its expression in tissues affected by the mutation, most likely represents the mouse $T$ gene (Herrmann et al. 1990; Wilkinson et al. 1990). To test whether the product of this RNA is capable of rescuing the phenotype of Brachyury mice, we first characterized the structure of the genomic locus corresponding to the cDNA clone pme75 using a combination of sequencing of genomic subclones to identify the number and positions of exons and RNase protection and primer extension analysis to ascertain the transcriptional start site (data not shown). The cDNA lacks 50 bases of nontranslated $5^{\prime}$ sequence, which is contained within the same exon as the $5^{\prime}$ end of the cDNA. A 23-kb genomic fragment, including the entire transcribed sequences of the $T$ gene plus $8.3 \mathrm{~kb}$ of $5^{\prime}$ and $5 \mathrm{~kb}$ of $3^{\prime}$ nontranscribed flanking sequence (Fig. 1), was excised from cosmid c2.190 [isolated from a 129 strain genomic library (Herrmann et al. 1990)] using ClaI and injected into fertilized eggs derived from matings of $\mathrm{CBA} \times \mathrm{C} 57 \mathrm{Bl} / 6 \mathrm{~F}_{1}$ mice. This fragment can be detected either by polymerase chain reaction (PCR) using primers that amplify $220 \mathrm{bp}$ of a 352 -bp region of vector sequences present at the $5^{\prime}$ end of the transgene fragment (Figs. 1 and 3) or by genomic Southern blotting using a probe (190R10RS) that detects a TaqI polymorphism present between strain 129 and both CBA and C57Bl/6 mice (Fig. 2a; see Materials and methods). Of a total of 55 live-born offspring produced in three experiments, only 1 (designated 118.9) carried the transgene fragment, which was present as a single copy (Fig. 2a) and is referred to as $\mathrm{TG}^{T}$. This animal was phenotypically normal. Careful examination revealed no difference in tail phenotype compared with nontransgenic littermates. As 1 in 55 represents an unusually low rate of transgenesis /which is usually between $15 \%$ and $35 \%$ of live-born animals in our hands|, a further experiment was performed in which injected embryos were recovered after 9 days postreimplantation, at the four- to eight-somite stage. Of $21 \mathrm{em}$ bryos recovered, 7 tested positive for the presence of the transgene using PCR. This result suggests that the presence of extra copies of the $T$ gene may be deleterious to successful development to term, but as yet no obvious phenotype has been detected.

\section{Complementation of the tail phenotype of Brachyury mutants}

To test the ability of $\mathrm{TG}^{T}$ to substitute for the wild-type Brachyury allele, founder mouse 118.9 was crossed to mice that carried either the $T$ mutant version of chromosome 17 or the $T$ Curtailed $\left(T^{c}\right)$ allele. Like $T, T^{c}$ was $\mathrm{X}$-ray induced and exhibits an embryonic lethal homozygous phenotype; but, in contrast to the variable shorttailed phenotype of $T /+$ animals, heterozygous $T^{c}$ mice invariably completely lack tails and exhibit relatively high mortality between birth and weaning (Searle 1966). Both alleles result in a lethal homozygous phenotype, in which posterior regions of the embryo fail to form (see introductory section). Sequencing of the transcribed regions of Brachyury genomic clones isolated from a library produced from $T^{c} /+$ DNA revealed a 19-bp deletion in the 3' end of the open reading frame (from base 1269 to 1287 in Fig. 5 of Herrmann et al. 1990|, resulting in an altered predicted protein product in which the carboxy-terminal 50 amino acids are substituted for 32 unrelated residues. The presence of the $T^{c}$ allele in offspring

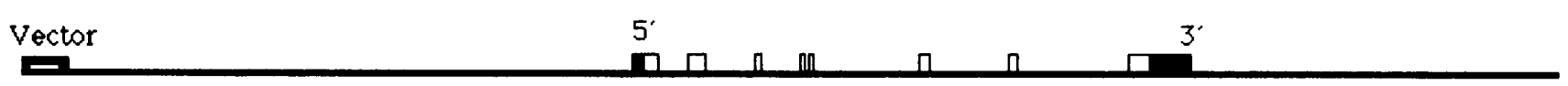

Figure 1. DNA fragment used to generate transgenic mice. Solid boxes indicate untranslated and open boxes translated exon sequences. Vector sequences used for detection of the transgene fragment are indicated at the left end. 


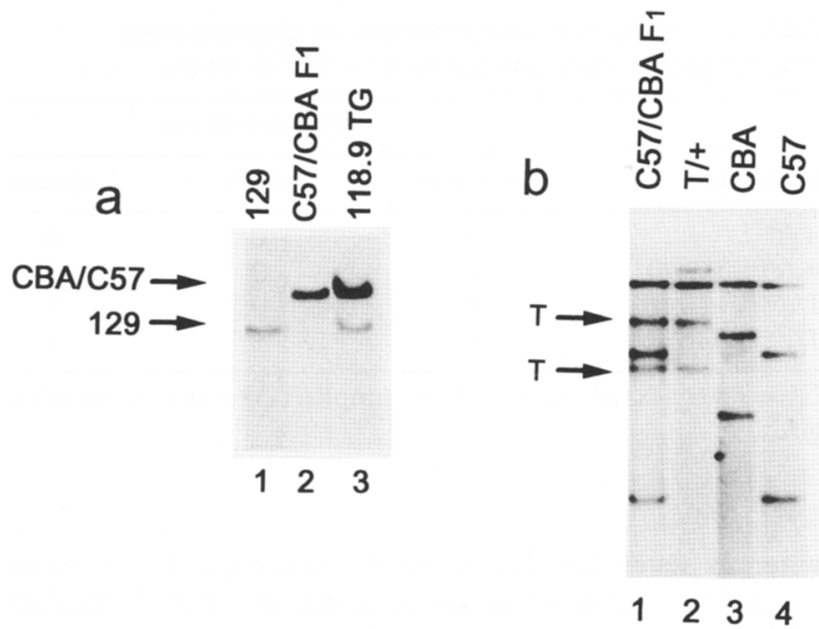

Figure 2. Genomic Southern blot detection of $\mathrm{TG}^{T}$ and $T(a)$ Autoradiograph of a Southern blot of Taq I-digested DNA hybridized with probe 190R10RS, which detects a TaqI polymorphism between CBA/C57Bl/6 and 129 strain mice within 1.2 $\mathrm{kb}$ of the transcriptional start of the $T$ gene. DNA was prepared from 129 (lane 1), $\mathrm{CBA} / \mathrm{C} 57 \mathrm{Bl} / 6 \mathrm{~F}_{1}$ (lane 2), or from transgenic founder 118.9 (lane 3). (b) Southern blot of BamHI-digested DNA hybridized with probe 119AR, which detects a BamHI polymorphism tightly linked to the $T$ deletion. (Lane 1) Progeny of $T /+$ crossed to CBA/C57Bl/6 $\mathrm{F}_{2}$; (lane 2) $T /+$; (lane 3) CBA; (lane 4) C57Bl/6. Arrows indicate bands tightly linked to the $T$ deletion.

was detected by PCR using primers that flank the 19-bp deletion (Fig. 3 ; data not shown), and the $T$ chromosome was demonstrated by Southern blotting using a probe (p119AR; probe C in Herrmann et al. 1987), which detects a BamHI polymorphism tightly linked to the $T$ deletion (Fig. 2b).

In crosses between 118.9 and a $T^{c} /+$ male, four litters

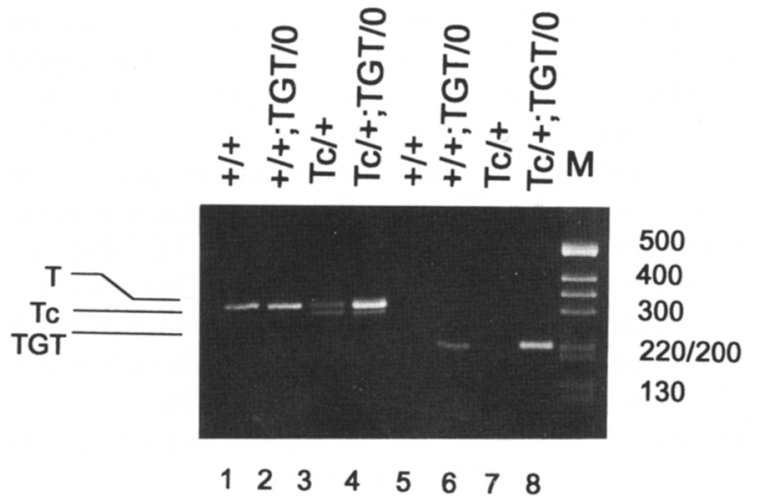

Figure 3. PCR detection of transgene and $T^{c}$ allele. Genomic DNA $(0.1-1 \mu \mathrm{g})$ was amplified using primer pairs that flank the 19-bp deletion in the $T^{c}$ allele (lanes 1-4) or amplify a 220 -bp region of vector sequences present in the transgene fragment (lanes 5-8). (Lanes 1,5) $+1+$; (lanes 2, 6) $+1+; \mathrm{TG}^{T} / 0$; (lanes 3 , 7) $T^{c} /+$; (lanes 4,8$) T^{c} /+$; $\mathrm{TG}^{T} / 0$; (lane 9) molecular weight markers $(M)$. Amplification products from the normal $T$ gene, $T^{c}$, and vector sequences linked to the transgene are indicated. were produced consisting of a total of 38 offspring; 12 of the 38 animals carried the $T^{c}$ allele in the absence of $\mathrm{TG}^{T}$ and were tailless, whereas 10 animals that carried the $T^{c}$ allele in the presence of $\mathrm{TG}^{T}$ all had short tails. The length of the tail varied from one-eighth to three-fourths of normal tail length. In crosses between 118.9 and a $\mathrm{T} /+$ male, three litters were produced consisting of 21 offspring; 7 carried the $T$ chromosome in the absence of $\mathrm{TG}^{T}$ and possessed short tails, whereas 6 animals carried both the $T$ chromosome and $\mathrm{TG}^{T}$ and had normal tails (Table 1). In second-generation crosses, animals carrying $\mathrm{TG}^{T}$ in the presence of the $T^{c}$ allele were mated to $T /+$ animals. The progeny were tested for $T, T^{c}$, and $\mathrm{TG}^{T}$. Of 13 animals carrying the $T^{c}$ allele plus $\mathrm{TG}^{T}, 11$ showed partial rescue of the tailless phenotype. Of 14 animals carrying the $T$ chromosome in the presence of $\mathrm{TG}^{T}, 13$ showed complete rescue of the short-tailed phenotype. A total of 15 animals, from both first- and second-generation crosses, carried three normal copies of the Brachyury gene $\left(+/+; \mathrm{TG}^{T} / 0\right.$; Table 1$)$. The tail length of these animals was measured but did not differ significantly from that of wild-type littermates.

\section{Correlation of the gene dosage of Brachyury with the extension of the anteroposterior axis}

To examine the effect of two copies of $\mathrm{TG}^{T}$ on the phenotype of $T^{c} /+$ mice, animals of the genotype $T^{c} /+$; $\mathrm{TG}^{T} / 0$ were intercrossed, and the genotype of the offspring was checked by PCR for the presence of the transgene and the $T^{c}$ allele. Animals in which both were present were tested for homozygosity by outcrossing and testing the offspring for the two sequences. A total of nine mice of the genotype $T^{c} /+; \mathrm{TG}^{T} / \mathrm{TG}^{T}$ were pro-

Table 1. Phenotypes and genotypes of first- and second-generation offspring from transgenic founder 118.9 $\left(+1+; T G^{\mathrm{T}} / 0\right)$ crossed to $\mathrm{T} /+$ or $\mathrm{T}^{\mathrm{c}} /+$ males

\begin{tabular}{|c|c|c|c|c|}
\hline \multirow[b]{2}{*}{ Genotype } & \multicolumn{4}{|c|}{ Tail phenotypes } \\
\hline & normal & short & absent & total \\
\hline \multicolumn{5}{|c|}{ First-generation crosses $\left(118.9 \times T^{c} /+\right)$} \\
\hline$T^{c} /+$ & 0 & 0 & 12 & 12 \\
\hline$T^{c} /+{ }_{;} \mathrm{TG}^{T} / 0$ & 0 & 10 & 0 & 10 \\
\hline$+1+$ & 6 & 0 & 0 & 6 \\
\hline$+/+; \mathrm{TG}^{T} / 0$ & 10 & 0 & 0 & 10 \\
\hline \multicolumn{5}{|c|}{ First-generation crosses $(118.9 \times T /+)$} \\
\hline$T /+$ & 0 & 7 & 0 & 7 \\
\hline$T /+; \mathrm{TG}^{T} / 0$ & 6 & 0 & 0 & 6 \\
\hline$+1+$ & 7 & 0 & 0 & 7 \\
\hline$+/+; \mathrm{TG}^{T} / 0$ & 1 & 0 & 0 & 1 \\
\hline \multicolumn{5}{|c|}{ Second-generation crosses $\left(T^{c} /+; \mathrm{TG}^{T} / 0 \times T /+\right)$} \\
\hline$T^{c} /+$ & 0 & 0 & 12 & 12 \\
\hline$T^{c} /+; \mathrm{TG}^{T} / 0$ & 0 & 11 & 2 & 13 \\
\hline$+1+$ & 19 & 0 & 0 & 19 \\
\hline$+/+; \mathrm{TG}^{T} / 0$ & 4 & 0 & 0 & 4 \\
\hline$T /+$ & 0 & 4 & 0 & 4 \\
\hline $\mathrm{T} /+; \mathrm{TG}^{T} / 0$ & 13 & 1 & 0 & 14 \\
\hline
\end{tabular}

Litters were examined and DNA samples taken at 4 weeks after birth. 
duced, of which one possessed a short tail and eight possessed blunt tails / the description blunt is used for a tail phenotype in which the tail length is essentially normal but the tail tip is rounded rather than pointed as in wildtype animals). This represents a distinct increase of tail length in comparison to mice of the genotype $T^{c} /+$; $\mathrm{TG}^{T} / 0$, for which 11 of the 13 animals typed had short tails and the other 2 were tailless. No animals were recovered that proved homozygous for the $T^{c}$ allele (Table 2 ), suggesting that $\mathrm{TG}^{T}$, present in either one or two copies, is unable to rescue this genotype.

\section{Interaction of $\mathrm{t}$ chromosomes with $T G^{T}$}

The presence of $t$ forms of chromosome 17 has been shown to enhance the tail phenotype of the $T$ mutation; animals of the genotype $T / t$ are tailless, whereas $t /+$ heterozygotes have a normal tail. The locus on $t$ chromosomes responsible for this effect has been designated tct and postulated to be an allele of $T$ with less than normal activity (Justice and Bode 1988). To test this idea, we crossed mice in which the short-tailed phenotype of $T$ heterozygotes had been rescued completely by the activity of $\mathrm{TG}^{T}$ with mice carrying $t$ forms of chromosome 17. If $t c t$ is a $T$ allele with less than normal activity, then $T / t ; \mathrm{TG}^{T} / 0$ mice should show a normal phenotype-the $T$ deficiency being compensated by the product of $\mathrm{TG}^{T}$ $(t)+$ animals have normal tails $)$ - provided $\mathrm{TG}^{T}$ has normal gene activity. Alternatively, if the tct effect is mediated by interaction with a different gene, then $\mathrm{TG}^{T}$ will be unable to rescue the effect. The partial $t$ haplotype $t^{h 51}$ (Lyon 1984) was chosen for these experiments. Unlike complete $t$ haplotypes, $t^{h 51}$ has the advantage that homozygous animals are viable, simplifying the genotypic analysis of the offspring. The homozygous nature of $t^{h 51}$ was verified by the presence of a $t$ chromosome in all offspring, checked by Southern blot analysis (data not shown; see Materials and methods). A total of seven animals of the genotype $T / t^{h 51} ; \mathrm{TG}^{T} / 0$ were produced; six had short tails, the other being tailless,

Table 2. Phenotypes and genotypes of offspring from $\mathrm{T}^{\mathrm{c}} /+; T G^{\mathrm{T}} / 0$ female mice crossed to males of the same genotype

\begin{tabular}{lcccc}
\hline & \multicolumn{4}{c}{ Tail phenotypes } \\
\cline { 2 - 5 } Genotype & normal & blunt & short & absent \\
\hline$+l+$ & 7 & 0 & 0 & 0 \\
$+/+; \mathrm{TG}^{T} / ?^{\mathrm{a}}$ & 10 & 0 & 0 & 0 \\
$T^{c} /+$ & 0 & 0 & 0 & 4 \\
$T^{c} /+\mathrm{TG}^{T} / 0$ & 0 & 0 & 11 & 2 \\
$T^{c} /+; \mathrm{TG}^{T} / \mathrm{TG}^{T}$ & 0 & 8 & 1 & 0 \\
\hline
\end{tabular}

Animals were tested by PCR for $T^{c}$ and $\mathrm{TG}^{T}$. Where both were present, homozygosity was tested by outcrossing to wild-type mice and examining the progeny for the presence of $T^{c}$ and $\mathrm{TG}^{T}$. Litters were examined and DNA samples taken at 4 weeks after birth.

a Animals that tested negative for $T^{c}$ and positive for the transgene were not tested for transgene homozygosity.
Table 3. Phenotypes and genotypes of offspring from $\mathrm{t}^{\mathrm{h} 51} / \mathrm{t}^{\mathrm{h} 51}$ female mice crossed to $\mathrm{T} /+; T G^{\mathrm{T}} / 0$ males

\begin{tabular}{lccc}
\hline & \multicolumn{3}{c}{ Tail phenotypes } \\
\cline { 2 - 4 } Genotype & normal & short & absent \\
\hline$+/ t^{h 51}$ & 3 & 0 & 0 \\
$+/ t^{h 51} ; \mathrm{TG}^{T} / 0$ & 6 & 0 & 0 \\
$\mathrm{~T} / t^{h 51}$ & 0 & 0 & 7 \\
$T / t^{h 51} ; \mathrm{TG}^{T} / 0$ & 0 & 6 & 1 \\
\hline
\end{tabular}

Litters were examined and DNA samples taken at 4 weeks after birth.

whereas seven littermates of the genotype $T / t^{h 51}$ were all tailless (Table 3). In no case did the $T / t^{h 51} ; \mathrm{TG}^{T} / 0$ genotype result in a normal tail.

\section{Expression pattern of $T G^{T}$}

One explanation for the inability of $\mathrm{TG}^{T}$ to rescue the effect of $t c t$ would be that $\mathrm{TG}^{T}$ is not expressed in the cells in which the interaction between tct and $T$ occurs. To assess the expression pattern of $\mathrm{TG}^{T}$, the distribution of $T$ message in embryos from time-mated $T /+$ females paired with $T /+$; $\mathrm{TG}^{T} / 0$ males was assessed by in situ hybridization. Embryos were isolated at 7.75 days of development, before the lethal phenotype of $T / T$ embryos is apparent but after formation of the two major sites of expression of the $T$ gene, the primitive streak mesoderm, and the notochord precursor (Wilkinson et al. 1990). Embryos were dissected free of maternal tissues and processed for whole-mount in situ hybridization, using an antisense probe synthesized from coding sequences of the $T$ gene (Herrmann 1991). A total of 54 embryos derived from $T /+\times T /+; \mathrm{TG}^{T}$ crosses were hybridized, of which 49 embryos exhibited a normal distribution of TRNA; the remaining 5 showing no specific hybridization. In this cross, $\sim 25 \%$ of embryos are expected to be of the genotype $T / T$; half of these will carry the transgene and half will not. That $<12.5 \%$ of the embryos showed no hybridization suggests that these embryos are $T / T$ and that embryos of the genotype $T / T ; \mathrm{TG}^{T} / 0$ are indistinguishable in their hybridization pattern from embryos carrying a wild-type $T$ gene. It remains possible that the level of product produced from $\mathrm{TG}^{T}$ differs significantly from that of a normal allele. This point could not be addressed using the in situ approach described, which is unlikely to be quantitative. Although this possibility cannot be excluded, we consider it unlikely, based on the ability of $\mathrm{TG}^{T}$ to completely complement the tail phenotype of $T /+$ animals.

\section{Discussion}

The processes responsible for anteroposterior axis formation in the mammalian embryo are as yet poorly understood (Gurdon 1992). One of the reasons for this is the difficulty of direct experimental manipulation of the embryo at the time immediately after implantation to ma- 
ternal tissues when the first events of axis determination probably occur (Smith 1985). To try to understand some of the processes that are involved in the formation of the axis, we have begun to study the properties of a gene, $T$, or Brachyury, the function of which is known from the phenotype of mutants to be required during this event.

As a first approach to this, we attempted to produce transgenic mice carrying extra copies of the $T$ gene. The success rate of this procedure was unusually low; $<2 \%$ of live-born progeny were transgenic, suggesting a deleterious effect of the transgene on embryo survival. Furthermore, the one transgenic animal that survived to birth had a single copy of the transgene fragment integrated into the genome. Single-copy transgenes are normally relatively rare, suggesting selection for low-copynumber insertions in this experiment. When embryos were isolated early in development, the rate of integration of the transgene fragment used was within the range usually experienced in our laboratory $(20-35 \%)$. However, no phenotype was observable at the gross level in embryos at early somite stages. One effect of mutations at the $T$ locus is a reduction of cells allocated to the mesodermal component of embryos, whereas the ectoderm contains too many cells (Yanagisawa et al. 1981). It may be that embryos expressing the $T$ gene above a certain level commit too many cells to the mesoderm, leaving insufficient cells to form ectoderm-derived structures. An alternative possibility might be, as we have demonstrated here, that as the embryo needs increasing amounts of $T$ product at posterior positions along the anteroposterior axis, a high dosage of $T$ product anteriorly might alter the fate of the mesodermal derivatives, resulting in an embryo with abnormal anterior structures. Either of these effects could lead to embryonic lethality. We intend to address this point by constructing transgenes to over express the $T$ product in the mesodermal tissues of the early embryo to look for an observable, associated phenotype.

Despite an apparent strong selection against the transgene during generation of transgenic founder animals, $\mathrm{TG}^{T}$ is transmitted in a normal, Mendelian fashion in $+/+$ mice. This probably reflects an adjustment of the level of expression from all copies of the gene. In this respect it is noteworthy that a chromosome containing a duplication of $T$, while initially thought to cause homozygous lethality, was eventually bred to homozygosity (Styrna and Klein 1981). The presence of loci in the mouse genome, which can have a cumulative effect on the level of the expression of the transgene (and presumably the endogenous) loci over subsequent generations, has been reported (Allen et al. 1990).

\section{Complementation of the T-associated tail phenotype}

The single-copy transgene insertion $\mathrm{TG}^{T}$ results in complete rescue of the short-tailed phenotype of $T /+$ animals in the majority (six of seven) of cases. The $T$ mutant is known to be a true null by virtue of being a deletion of all coding sequences of the $T$ gene (Herrmann et al. 1990). This suggests that either the activity of $\mathrm{TG}^{T}$ is similar to that of the wild-type locus or that in the wildtype situation the $T$ product is not limiting and other factors determine the maximum extent of the axis. In either case, the complete restoration of the wild-type phenotype demonstrates that the transcription unit in the cosmid c2.190, corresponding to the cDNA pme75, represents the $T$ gene.

The $T^{c}$ allele produces an altered protein product that results in a more extreme phenotype than the null allele in the heterozygous situation. As suggested previously (MacMurray and Shin 1988), this probably results from an antimorphic function of the $T^{c}$ product. Interestingly, at least two other $T$ alleles with severe heterozygous phenotypes have mutations causing an altered carboxyterminal peptide sequence, $T^{\text {Wis }}$ (Herrmann et al. 1990) and $T^{C-2 H}$ (A. Kispert and B.G. Herrmann, unpubl.), suggesting a distinct function for the carboxy-terminal portion of the protein. The murine $T$ protein shows nuclear localization in embryonic mesoderm (A. Kispert and B.G. Herrmann, in prep.), suggesting a regulatory role for the $T$ product in transcription or RNA processing. A reasonable hypothesis to explain the activity of these variant $T$ products is that the protein interacts with at least two other entities and that the modified carboxyl terminus is deficient in one of these interactions. The aminoterminal portion of the protein-coding sequence is very highly conserved between mice (Herrmann et al. 1990), Xenopus (Smith et al. 1991), and zebra fish (SchulteMerker et al. 1992), suggesting a conserved function for this region, possibly DNA binding. It is possible that the $T$ protein interacts with one or more proteins as well as a nucleic acid sequence. The carboxy-terminal mutation of the $T^{c}$ product would allow one of these interactions to take place while preventing the other, having the effect of blocking the function of the wild-type product, causing a $>50 \%$ reduction in effective $T$ protein activity.

Complementation of the $T^{c}$ phenotype with $\mathrm{TG}^{T}$ resulted in mice with short rather than normal tails. This incomplete restoration of the wild-type phenotype probably results from the continued presence of the $T^{c}$ product, which now competes with the wild-type product from both the transgene and endogenous wild-type locus. Apparently the effective $T$ protein activity in this configuration is similar to that in $\mathrm{T} /+$ heterozygotes, which should be $\sim 50 \%$ of the normal level. On addition of a third wild-type copy of $T$, the phenotype is restored further, resulting in blunt-tailed mice, but the axis still fails to reach the normal extent. It has been postulated previously that extension of the axis requires an increasing dose of $T$ activity at progressively posterior positions (Yanagisawa 1990). These data support this idea and demonstrate directly the involvement of the $T$ product in axial extension in the mammalian embryo.

In our experiments no offspring were produced that were homozygous for $T^{c}$, as would be anticipated if the activity of the transgene were as great as that of the wild-type locus $\left(T^{c} /+; \mathrm{TG}^{T} / 0=T^{c} / T^{c} ; \mathrm{TG}^{T} / \mathrm{TG}^{T}\right)$. Presumably, the product from two copies of the transgene is insufficient to overcome the negative effect of two copies of $T^{c}$, resulting in prenatal lethality. As has been 
shown previously, $T^{c} /+$ heterozygotes also have reduced viability (Searle 1966)

\section{Identity of the tct locus of $\mathrm{t}$ haplotypes}

The $t c t$ locus was identified by the effect on the tail phenotype observed in crosses of $t$ haplotype carrying mice with $T /+$ mice. In the presence of a $t$ haplotype chromosome, the $T$ short-tailed phenotype is enhanced to a tailless phenotype similar to that of mice heterozygous for antimorphic $T$ alleles. A mutation chemically induced on an inbred strain chromosome, $t c t^{k}$, interacting with $T$ like $t c t$, has been mapped genetically to the $T$ locus (Bode 1984). It has been suggested that $t c t^{k}$, as well as tct, may represent a hypomorphic $T$ allele with reduced activity (Justice and Bode 1988). Neither the induced mutation nor the $t$ chromosome in heterozygous $(t /+)$ or homozygous $(t / t)$ mice has a tail phentype. The transgene $\mathrm{TG}^{T}$ restores completely the tail phenotype of $\mathrm{T} /+$ mice in the majority of cases (Table 1). If $\mathrm{TG}^{T}$ had normal gene activity, it would be expected to complement the tail phenotype of $T / t$ mice $\left(T / t ; \mathrm{TG}^{T} / 0=+1\right.$ $t$ ), which is not the case. Instead, the effect of $\mathrm{TG}^{T}$ in $T / t$ mice is similar to that in $T^{c} /+$ mice. Either $\mathrm{TG}^{T}$ has reduced activity or tct is a mutation in a different locus, which is not complemented by $\mathrm{TG}^{T}$ and is closely linked to $T$. If the latter were true, tct might also be missing from the $T$ deletion, which extends over $\sim 200 \mathrm{~kb}$ and is likely to affect several genes. It would follow that in $T / t ; \mathrm{TG}^{T} / 0$ mice, the product of the $t c t$ locus would be limiting for axial development because the normal dosage of the $T$ gene would be restored while there was only a single copy of the tct locus, probably with abnormal activity.

\section{Possible function of the $\mathrm{T}$ gene product}

We and others have observed that the node of homozygous mutant $T$ embryos is the first structure visibly affected by a lack of functional $T$ product (Fujimoto and Yanagisawa 1983; Herrmann 1991). In addition, it has been shown that the $T$ product is required in a cell-autonomous fashion for the maintenance and differentiation of notochord cells and some streak-derived cells (Rashbass et al. 1991) and that the $T$ product is localized to the nucleus (Schulte-Merker et al. 1992; A. Kispert and B.G. Herrmann, in prep.). A simple proposal, based on these data, is that the $T$ gene product is required for the regulation of genes involved in establishing mesodermal, in particular notochordal, cell fates. Our future efforts will be directed at identifying genes regulated by the $T$ product. This should enhance our understanding of differentiation processes, especially those involved in the formation of the embryonic axis of vertebrates.

\section{Materials and methods}

DNA and RNA analyses

DNA manipulations were performed according to standard procedures (Sambrook et al. 1989), using the cosmid c2.190 as start- ing material (Herrmann et al. 1990). Selected fragments were subcloned into pBluescript vectors (Stratagene), and doublestranded templates were sequenced using a Sequenase kit (U.S. Biochemical) according to the manufacturers' instructions.

RNase protection and primer extension analyses to ascertain the transcriptional start of the $T$ gene were performed according to published protocols (Ausubel et al. 1987) using probes complimentary to the $5^{\prime}$ region of pme 75 .

\section{Transgenic mice}

Procedures were essentially the same as those described (Hogan et al. 1986). Briefly, a 23-kb fragment was excised from $\mathrm{c} 2.190$ (Herrmann et al. 1990) with ClaI and purified on a $0.6 \%$ lowmelting-temperature agarose gel containing $1 \mu \mathrm{g} / \mathrm{ml}$ of ethidium bromide. The fragment was excised under longwave UV illumination, the agarose was removed by phenol extraction, and the DNA was precipitated with ethanol. The fragment was subsequently purified on an Elutip-D column (Schleicher \& Schuell), according to the manufacturers' instructions, and injected at $1 \mu \mathrm{g} / \mathrm{ml}$ into the male pronucleus of fertilized eggs isolated from superovulated $\mathrm{CBA} \times \mathrm{C} 57 \mathrm{Bl} / 6$ female mice mated to males of the same genotype. Tail biopsies were taken at 4 weeks, and DNA was extracted by overnight digestion at $55^{\circ} \mathrm{C}$ with proteinase $\mathrm{K}$ at $100 \mu \mathrm{g} / \mathrm{ml}$.

\section{PCR analysis}

Amplification of DNA fragments for detection of transgenes and $T$ alleles was performed using $0.1-1 \mu \mathrm{g}$ of genomic DNA in $20 \mu \mathrm{l}$ of $10 \mathrm{mM}$ Tris- $\mathrm{HCl}(\mathrm{pH} 8.8) ; 1.5 \mathrm{mMMgCl}_{2} ; 50 \mathrm{mM} \mathrm{KCl}$; $100 \mu \mathrm{g} / \mathrm{ml}$ of BSA; $0.25 \mathrm{~mm}$ each of dATP, dCTP, dGTP, and TTP; 1 unit of Taq polymerase (Amersham), and $100 \mathrm{ng}$ of each primer. Amplification was achieved by using 30 cycles of $95^{\circ} \mathrm{C}$ for $0.5 \mathrm{~min}$; hybridization temperature was optimized for specific primer pair $\left(49-60^{\circ} \mathrm{C}\right)$ for $1 \mathrm{~min}$; and $72^{\circ} \mathrm{C}$ for $1 \mathrm{~min}$. The primers $\left(5^{\prime} \rightarrow 3^{\prime}\right)$, hybridization temperatures, and product sizes were as follows. For detection of $\mathrm{TG}^{T}$; primers 033 (TGGTCGCCATGATCGCGTAGTCG) and 034 (GTAGGCATAGGCTTGGTTATGGCC) were used with a hybridization temperature of $49^{\circ} \mathrm{C}$, giving a product of $220 \mathrm{bp}$. For detection of $T^{c}$; primers 022 (CCAGTTGACACCGGTTGTTACA) and 040 (TATCCC. AGTCTCTGGTCTGT) were used with a hybridization temperature of $55^{\circ} \mathrm{C}$ giving a product of $320 \mathrm{bp}$ for the wild-type and $301 \mathrm{bp}$ for the $T^{c}$ allele. The entire reaction product was electrophoresed on a $2.4 \%$ agarose gel containing $1 \mu \mathrm{g} / \mathrm{ml}$ of ethidium bromide and photographed under shortwave UV illumination.

\section{Genomic Southern blotting}

Twenty micrograms of genomic DNA was digested and blotted to Hybond $\mathrm{N}^{+}$filters (Amersham) as described previously (Herrmann et al. 1990|. Probes were synthesized by random priming of isolated DNA fragments (Feinberg and Vogelstein 1984) and hybridized according to the procedure of Church and Gilbert (1984). Digests and probes were as follows. For detection of $\mathrm{TG}^{T}$, digestion was performed with TaqI and probing with 190R10RS, which detects a TaqI polymorphism between both CBA and $\mathrm{C} 57 \mathrm{Bl} / 6$ strain mice and those of the 129 strain, located within $1.2 \mathrm{~kb}$ of the transcriptional start of the $T$ gene. This probe also detects a third, different fragment in $t$ chromosomes, allowing verification of homozygosity of the $t^{\text {h51 }}$ animals used in this study. For detection of $T$ chromosomes, digestion was performed with BamHI and probing with 119AR, which detects a BamHI polymorphism; this is tightly linked to the $T$ deletion (Herrmann et al. 1990). 


\section{Whole-mount in situ hybridization}

Embryos were isolated from $T /+$ females mated to $T /+$, $\mathrm{TG}^{T} / 0$ males, at 7.75 days postcoitum, fixed in $4 \%$ paraformaldehyde overnight at $4^{\circ} \mathrm{C}$, and stored in ethanol at $4^{\circ} \mathrm{C}$. Embryos of the desired genotype, plus appropriate littermates as controls, were hybridized with a biotinylated antisense $T$ probe as described previously (Herrmann 1991).

\section{Acknowledgments}

We thank Dorothee Weigel, Agathe Authaler, and Tatjana Sick for technical assistance; Mary Lyon and Karen Artzt for $T^{c} /+$ mice; H. Sinner for maintenance of stocks; Uli Schwarz for support, and Jacques Paysan and Hubert Ortner for discussion. B.G.H. thanks Hans Lehrach for fruitful discussions and support. D.S. was supported by the Royal Society during the first part of this work, which was funded by the Deutche Forschungsgemeinschaft.

The publication costs of this article were defrayed in part by payment of page charges. This article must therefore be hereby marked "advertisement" in accordance with 18 USC section 1734 solely to indicate this fact.

\section{References}

Allen, N.D., M.L. Norris, and M.A. Surani. 1990. Epigenetic control of transgene expression and imprinting by genotypespecific modifiers. Cell 61: 853-861.

Ausubel, F.M., R.M. Brent, R.E. Kingston, D.D. Moore, J.G. Seidman, D. Smith, and K. Struhl. 1987. Current protocols in molecular biology. John Wiley, New York.

Beddington, R.S.P., J. Morgernstern, H. Land, and A. Hogan. 1989. An in situ transgenic enzyme marker for the midgestation mouse embryo and the visualisation of inner cell mass clones during early organogenesis. Development 106: 37-46.

Bode, V.C. 1984. Ethylnitrosourea mutagenesis and the isolation of mutant alleles for specific genes located in the $T$ region of mouse chromosome 17. Genetics 108: 457-470.

Chesley, P. 1935. Development of the short-tailed mutant in the house mouse. J. Exp. Zool. 71: 429-459.

Church, G.M. and W. Gilbert. 1984. Genomic sequencing. Proc. Nat1. Acad. Sci. 81: 1991-1995.

Feinberg, A.P. and B. Vogelstein. 1984. A technique for radiolabelling DNA restriction endonuclease fragments to high specific activity. Anal. Biochem. 137: 266-267.

Fujimoto, H. and K.O. Yanagisawa. 1983. Defects in the archenteron of mouse embryos homozygous for the $T$-mutation. Differentiation 25: 44-47.

Gardner, R.L. and V.E. Papaioannou. 1975. Differentiation in the trophectoderm and inner cell mass. In The early development of mammals (ed. M. Balls and A.E. Wild), pp. 107132, Cambridge University Press, Cambridge, England.

Gardner, R.L. and J. Rossant. 1979. Investigation of the fate of 4.5 day post coitum mouse inner cell mass cells by blastocyst injection. I. Embryol. Exp. Morphol. 52: 141-152.

Gardner, R.L., M.F. Lyon, E.P. Evans, and M.D. Burtenshaw. 1985. Clonal analysis of X-chromosome inactivation and the origin of the germ line in the mouse embryo. J. Embryol. Exp. Morphol. 88: 349-363.

Gluecksohn-Schoenheimer, S. 1938. The development of two tailless mutants in the house mouse. Genetics 23: 573-584.

- 1944. The development of normal and homozygous Brachy $(T / T)$ mouse embryos in the extraembryonic coelom of the chick. Proc. Natl. Acad. Sci. 30: 134-140.

Grueneberg, H. 1958. Genetical studies on the skeleton of the mouse XXIII: The development of Brachyury and Anury. $J$. Embryol. Exp. Morphol. 6: 424-443.

Gurdon, J.B. 1992. The generation of diversity and pattern in animal development. Cell 68: 185-199.

Herrmann, B.G. 1991. Expression pattern of the Brachyury gene in whole-mount $T^{\text {Wis }} / T^{\text {Wis }}$ mutant embryos. Development 113: 913-917.

Herrmann, B.G., D.P. Barlow, and H. Lehrach. 1987. A large inverted duplication allows homologous recombination between chromosomes heterozygous for the proximal $t$ complex inversion. Cell 48: 813-825.

Herrmann, B.G., S. Labeit, A. Poustka, T.R. King, and H. Lehrach. 1990. Cloning of the $T$ gene required in mesoderm formation in the mouse. Nature 343: 617-622.

Hogan, B., F. Constantini, and E. Lacy. 1986. Manipulating the mouse embryo. Cold Spring Harbor Laboratory, Cold Spring Harbor, New York.

Jurand, A. 1974. Some aspects of the development of the notochord in mouse embryos. I. Embryol. Exp. Morphol. 32: 1-33.

Justice, M.J. and V.C. Bode. 1988. New evidence supporting the allelism of $T$ and tct. Mouse Newslett. 80: 168-169.

Lawson, K.A., J.J. Meneses, and R.A. Pedersen. 1991. Clonal analysis of epiblast fate during germ layer formation in the mouse embryo. Development 113: 891-911.

Lyon, M.F. 1984. Transmission ratio distortion in mouse $t$-haplotypes is due to multiple distorter genes acting on a responder locus. Cell 37: 621-628.

MacMurray, A. and H.-S. Shin. 1988. The antimorphic nature of the $T^{c}$ allele at the mouse $T$ locus. Genetics 120: $545-550$.

Nakatsuji, N., M.L.H. Snow, and C.C. Wylie. 1986. Cinemicrographic study of the cell movement in the primitive-streakstage mouse embryo. J. Embryol. Exp. Morphol. 96: 99-109.

Rashbass, P., L.A. Cooke, B.G. Herrmann, and R.S.P. Beddington. 1991. A cell autonomous function of Brachyury in $\mathrm{T} / \mathrm{T}$ embryonic stem cell chimaeras. Nature 353: 348-351.

Sambrook, J., E.F. Fritsch, and T.' Maniatis. 1989. Molecular cloning: A laboratory manual. Cold Spring Harbor Laboratory Press, Cold Spring Harbor, New York.

Schulte-Merker, S., R.K. Ho, B.G. Herrmann, and C. NüssleinVolhard. 1992. The protein product of the zebrafish homologue of the mouse $T$ gene is expressed in nuclei of the germ ring and the notochord of the early embryo. Development 116: 1021-1032.

Searle, A.G. 1966. Curtailed, a new dominant $T$-allele in the house mouse. Genet. Res. Camb. 7: 86-95.

Smith, J.C., B.M.J. Price, J.B.A. Green, D. Weigel, and B.G. Herrmann. 1991. Expression of a Xenopus homologue of Brachyury $(T)$ is an immediate-early response to mesoderm induction. Cell 67: 79-87.

Smith, L.J. 1985. Embryonic axis orientation in the mouse and its correlation with blastocyst relationships to the uterus. $J$. Embryol. Exp. Morphol. 89: 15-35.

Spiegelman, M. 1976. Electron microscopy of cell associations in T-locus mutants. Embryogenesis in mammals. Ciba Found. Symp. 40: 199-220.

Styma, J. and J. Klein. 1981. Evidence for two regions in the mouse $\mathrm{t}$ complex controlling transmission ratios. Genet. Res. Camb. 38: 315-325.

Wilkinson, D.G., S. Bhatt, and B.G. Herrmann. 1990. Expression pattern of the mouse $T$ gene and its role in mesoderm formation. Nature 343: 657-659.

Yanagisawa, K.O. 1990. Does the $T$ gene determine the anteroposterior axis of a mouse embryo? Jpn. J. Genet. 65: 287-297.

Yanagisawa, K.O., H. Fujimoto, and H. Urushihara. 1981. Effects of the Brachyury $(T)$ mutation on morphogenetic movement in the mouse embryo. Dev. Biol. 87: 242-248. 


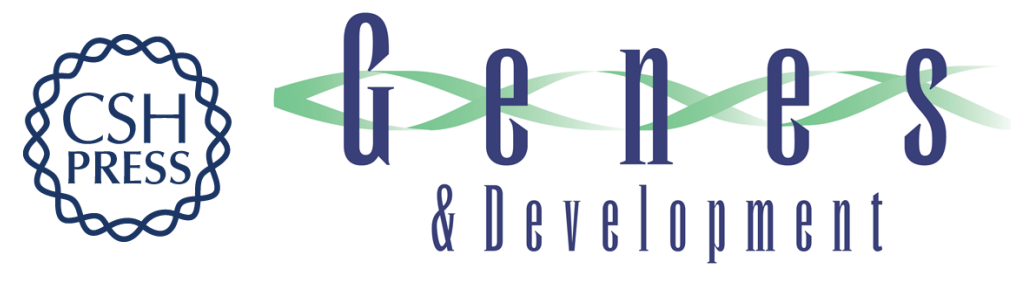

\section{Rescue of the tail defect of Brachyury mice.}

D Stott, A Kispert and B G Herrmann

Genes Dev. 1993, 7:

Access the most recent version at doi:10.1101/gad.7.2.197 $\begin{array}{ll}\text { References } & \begin{array}{l}\text { This article cites } 32 \text { articles, } 9 \text { of which can be accessed free at: } \\ \text { http://genesdev.cshlp.org/content/7/2/197.full.html\#ref-list-1 }\end{array}\end{array}$

License

Email Alerting Receive free email alerts when new articles cite this article - sign up in the box at the Service top right corner of the article or click here.

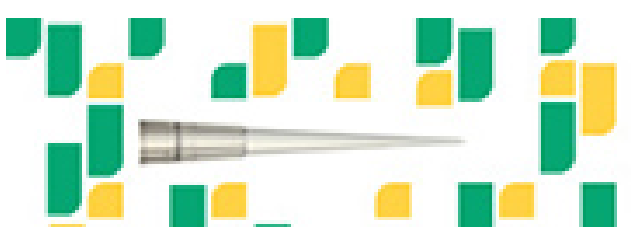

Focused on your science. 